\title{
Patterns of tidal flooding within a mangrove forest: Coombabah Lake, Southeast Queensland, Australia
}

\author{
J.M. Knight ${ }^{\text {a,b,c,1* }}$, P.E.R. Dale ${ }^{\text {a,c }}$, R.J.K. Dunn ${ }^{\text {d }}$, G.J. Broadbent ${ }^{\mathrm{e}}$, C.J. Lemckert ${ }^{\mathrm{a}, \mathrm{d}}$ \\ ${ }^{a}$ Cooperative Research Centre for Coastal Zone, Estuary and Waterway Management \\ ${ }^{b}$ School of Geography, Planning and Architecture, University of Queensland, St Lucia, Australia 4072 \\ ${ }^{c}$ Griffith School of Environment, Griffith University Nathan Campus, Nathan, Australia 4111 \\ ${ }^{d}$ School of Engineering, Griffith University Gold Coast Campus, PMB 50 Gold Coast Mail Centre, \\ Queensland, Australia 9726 \\ ${ }^{e}$ Maritime Safety, Queensland Mineral House, 41 George St, GPO Box 2595 Brisbane, Australia 4001
}

*Corresponding author:

Jon M. Knight

School of Geography, Planning and Architecture, University of Queensland, St Lucia, Australia 4072 Tel: +61 737357995

Fax: +61 737356717

Email address: j.knight@griffith.edu.au (Jon M. Knight)

\footnotetext{
${ }^{1}$ Present address: Griffith School of Environment, Griffith University, Nathan, Queensland, Australia, 4111.
} 


\section{Abstract}

Tidal flooding and surface drainage patterns have often been used to describe mangrove species zonation. However, in mangrove forests exhibiting little topography and ambiguous species distributions and/or few species, such approaches are ineffective. We developed four physiognomic mangrove forest types (Riverine, Fringing, Overwash and Basin) at Coombabah Lake, a tidal lake in southeast Queensland, Australia and investigated tidal flooding patterns using synoptic surveys of tidal observations at the local standard port combined with local water depth observation. Subsequently three sub-types of the basin forest type were identified: 1) Deep Basin Forest with mature trees, $\sim 50 \mathrm{~cm}$ standing water and $\sim 3$ tides per year; 2) Medium Depth Basin Forest with intermediate tree development, 15 - $30 \mathrm{~cm}$ standing water and 20 - 40 tides per year; and 3) Shallow Basin Forest with relatively recent mangrove establishment, 5 $15 \mathrm{~cm}$ standing water and $\sim 80$ tides per year. These three basin sub-types were found to flood at different tide heights with the Shallow Basin flooding only for tides above mean high water springs and the Deep Basin flooding for tide heights approaching the highest astronomical tide. We propose that these basin types represent a succession in mangrove forest development that corresponds with increasing water depth and tree maturation over time. The succession not only represents increasing age but also change in basin substrate composition. This is manifest as increasing pneumatophore density and an increasing area of basin surface occupied by contiguous pneumatophore cover. As a result, it seems that mangrove development is able to modify tidal flooding into the basin by increasingly impeding water movement.

Keywords: Mangroves, Tidal analysis, Intertidal environment, Hydrology, Australia. 


\section{Introduction}

Mangrove forests occupy zones of transition between terrestrial and marine ecosystems. It is generally understood that intertidal wetland characteristics are determined by the cumulative and complex interactions between hydrology, landscape position, sediment dynamics, storm-driven processes, sea level change, subsidence, colonization and disturbance by animals (Varnell et al. 2003). Indeed, Furukawa and Wolanski (1996) suggested that mangroves create their own ecosystems by trapping the sediment that forms their substrate. Factors important to mangrove tidal flooding patterns include vegetation density (for example, Wolanski et al. 1980; Wolanski 1992; Mazda et al. 1995; Mazda et al. 2005), evapotranspiration (Wolanski et al. 1980; Wolanski 1992), rainfall (Perdomo et al. 1998) and, in some cases, groundwater may be important (Wolanski 1992). Although the degree of influence that each of these has on structure and function of wetland systems varies, hydrology is the driving variable (Varnell et al. 2003).

The research into tidal flooding into mangroves has focussed on two areas: the processes of water movement in and out of mangroves; and the relationship between vegetation zonation and tidal flooding. In the current study patterns of tidal flooding into a mangrove system at Coombabah Lake in southeast Queensland, Australia, have been described. In order to understand tidal flooding in different parts of the system synoptic surveys are used to characterise the relationship between the tidal source and flooding within the forest.

Surface flow across mangroves largely determines the pattern of water under the canopy. It generally occurs as a result of rainfall events and during tidal flooding. As water enters the system, depressions are increasingly connected and a network of flow paths is eventually formed. Surface roughness is an important factor determining the surface flow in wetlands generally and this was modeled by Darboux et al. (2002), though not in an intertidal context. However, it is important in mangrove systems and Furukawa et al. (1997) showed that the density of above ground roots has an effect on the water movement, creating a large amount of friction. Recognising the importance of impediments to water movement in mangrove swamps Mazda et al. (2005) proposed a unifying theory of tidal scale hydrodynamics focusing on, inter alia, drag force related to vegetation. There has been considerable research on the role of vegetation and especially its density on tidal movement in channels (Wolanski et al. 1980) and over the mangrove swamp (Wolanski 1992; Furukawa and Wolanski 1996; Mazda et al. 1997; Mazda et al. 2005). Important as it is, describing the mechanisms for water flow across the mangrove surface in terms of drag forces is beyond the scope of the current research except to the extent that synoptic survey data allows, namely by inference from time delays in tidal traces readings.

Chapman (1976) summarised early research concerning tidal flooding into mangroves, citing Watson (1928), De Haan (1931), Chapman (1944), MacNae (1966), and others. The summary is described in the following sentences. Watson (1928) proposed five inundation classes according to tide height, ranging from all high tides through to storm high tides. De Haan (1931) built on Watson's work by examining the frequency of flooding within a monthly time frame, whilst also recognizing the continuum between saline and freshwater conditions, and related this to frequency of tidal flooding. Chapman (1944) extended De 
Haan's (1931) schema by considering flooding frequency on an annual time frame and associating this to species distribution. Other approaches such as Davis (1940) and later Macnae (1966) developed the mangrove zonation approach using dominant tree species as the basis and in so doing combined topographic position (a zonation from landward fringe through to seaward fringe) and dominant mangrove genera. For example, MacNae (1966) described mangroves in tropical northeastern Australi and suggested zonation ranging from landward Avicennia, Ceriops, Bruguieria and through to seaward Rhizophora and sometimes Avicennia. Chapman (1976 p192-3) proposed a variant of the species zonation idea by inverting inundation frequency and suggesting that "the most important aspect of the tidal phenomenon is the number of consecutive days at any one level when no tide covers the area”, arguing that the duration of continuous exposure is related to salt concentration in the upper soil layers. For example, extended exposure (corresponding with relatively few inundation events per year) leads to extreme salt build up and replacement of mangroves with areas of halophytes and then "a bare saltina”. However, the application of zonation schemas based on "successive monospecific mangrove zones", according to Lugo and Snedaker (1974 p4445), was most successfully applied where there was a steep shoreline gradient and not in situations of topographically flat shorelines, such as in south Florida mangroves. Likewise Macnae's schema is specific to tropical northeastern Australia, an area where mangroves reach their "most characteristic development" (Macnae 1966 p. 67), and is difficult to apply in areas such as southeastern Australia mangrove forests that comprise few species and, at their southern extent, include only one species (Avicennia marina var. australasica (Walp.)).

Lugo and Snedaker (1974 p 45) proposed an alternate mangrove forest schema based on mangrove physiognomy in six community types (fringe forest, riverine forest, overwash forest, basin forest, basin hummock forest and dwarf forest) where formation and physiognomy appeared to be "strongly controlled by local patterns of tides and terrestrial surface drainage”. In so doing they provided a mechanism for classification of mangrove forests where relatively flat topography and few mangrove species exist and emphasized the importance of local hydrology, particularly patterns of tidal dynamic and surface drainage. For example, by delineating basin forest and hammock basin forest as hydrologically distinct classes of mangrove forest, Lugo and Snedaker (1974) took into account a range of hydrologic conditions not considered otherwise.

There appears to have been limited research into identifying which tides flood a mangrove forest. Cohen et al. (2004) and Lara and Cohen (2006) in their research in Northern Brazil did relate high tides recorded at a distance of $100 \mathrm{~km}$ from the study site with local gauge data for part of the time and with a high resolution digital elevation model (DEM). They built their digital elevation model from a 1:1000 topographic map and used this to interpolate an elevation grid across their site which comprised mangroves exhibiting a riverine / fringe forest form, based on Lugo and Snedaker (1974). In order to map inundation frequency and depth across their site, they modeled inundation between their tide gauge sites and the extent of the mangrove using the DEM. The suitability of this approach with the current research is limited because we have no high resolution topographic data or DEM. The upslope extent of the mangroves (at Coombabah Lake) has not been linked to the elevation topography and there appears to be considerable micro-topographical variation that 
inhibits an interpolation of elevation. Some alternate approach is required to map the inundation patterns of mangroves in the study area (Coombabah Lake).

Having identified gaps in the knowledge base of mangrove flooding patterns, the aim of the research reported here was to quantify tidal flooding patterns for the Coombabah Lake intertidal system. This needed assessment not only of the forest forms but also details of tides at the local standard port, within the lake Coombabah Creek and within the mangrove forest system. The specific objectives were to:

1. observe forest forms in the field and relate these to forms reported in the literature;

2. To present a detailed analysis of tidal characteristics through synoptic surveys including:

a. for the local standard port - identifying tidal characteristics using long-term (19 years) tidal observations;

b. for the tidally unimpeded lake and associate creek- relating their phase shifts and amplitude differences to observations at the standard port; and

c. within the mangrove forest - identifying tidal inundation patterns (surface flooding).

The data presented here were gathered as part of a comprehensive case study of the impact of urbanization on coastal wetlands and was published in part in Knight et al. (2006).

\section{Methods}

\subsection{Study Area}

The study area is a system of mangrove forests associated with Coombabah Lake in southeast Queensland, Australia (153²0'W 2754'S) (Fig. 1). Coombabah Lake is a tidal lake located on Coombabah Creek, approximately $6 \mathrm{~km}$ from Moreton Bay. The mangrove forest is comprised mainly of the Grey Mangrove (Avicennia marina var. australasica (Walp.)), forming dense stands in low-lying areas connected to the lake (Fig 2). Also, a mix of mangrove genera including Avicennia, Ceriops, Bruguieria and Rhizophora is found in narrow fringes immediately adjacent to the lake edge (grouped with Avicennia marina as mangroves in Fig. 2 and associated with the Riverine forest type). Surrounding the lake at slightly higher elevations are three other wetlands vegetation communities including saltmarsh communities dominated by a mix of Sarcocornia quinqueflora (Bunge ex Ung.-Stern) and Sporobolus virginicus (L. Kunth) and mixed forest stands dominated by Casuarina glauca (Sieber ex Sprengel) and Melaleuca quinquenervia ((Cav.) S.T. Blake)) (Dowling and Stephens 2001, Fig. 2). The lake edge-mangrove interface is approximately $20 \mathrm{~km}$ in length with mangroves extending inland a distance ranging between about 5 and $700 \mathrm{~m}$, and commonly extending to $400 \mathrm{~m}$ inland.

\section{INSERT FIG 1}




\section{INSERT FIG 2}

\subsection{Data collection}

\subsubsection{Mangrove Forest Forms}

An assessment of mangrove forest form, based on Lugo and Snedaker (1974), was undertaken by field observation to identify different structural forms and to guide pressure logger deployment.

\subsubsection{Published Tide Data}

Official tide data were acquired for the Gold Coast tidal station (Marine Operations Base, Southport tidal station \#100035) from the Tidal Unit, Maritime Safety Queensland (MSQ), and included tide predictions and tide observations corresponding to the timing of each pressure logger deployment in the study. The Tidal Unit, MSQ, also provided 19 years of observation data for high tides above 1.3m and high and low tidal exceedence data. The 19 years of observations extended for 6940 days from 1st January 1986 until 31st December 2004. A total of 12520 high tides were recorded, with no readings on 534 days.

Tidal observation data for the period 5th-19th June 1998 from a tidal study conducted in the southern section of Coombabah Lake at a location known as the Crab Farm (MSQ tidal station \#001027A) and for the Gold Coast tidal station were also provided by the Tidal Unit, MSQ.

\subsubsection{Meteorological Data}

Air pressure data were obtained from the Queensland Bureau of Meteorology, Brisbane, for the Gold Coast Seaway Weather Station for each pressure logger deployment. Half hourly air pressure data, corrected to mean sea level, were used to correct logger pressure readings as described below.

\subsubsection{Water Depth Data}

Two types of pressure sensor loggers were used to record water depth during the study: Greenspan loggers (PS310 and CTD350) and Ocean Sensor Systems loggers (Wave Gauge OSSI-010-003B). The Greenspan loggers were set to acquire five readings at two-second intervals every ten minutes, recording the average of the five reading for each ten minute interval. The Ocean sensor Systems wave gauges were set to record pressure at two $\mathrm{Hz}$ for one minute every ten minutes with the average of the ten highest readings used as the reading for each ten minute interval.

There were 21 deployments of pressure loggers at 18 locations in the study area (Fig.2) during the study. One site (Site 1 - Pool 3) was sampled on four occasions and all others were sampled once. The repeat sampling of Pool 3 was undertaken partly because the site did not flood during initial deployments and also to provide a degree of continuity with, and reference for, subsequent deployments as part of the evolving study. A $19^{\text {th }}$ site (near the southern end of the lake, Fig. 2) indicates the estimated position of a logger deployment 
by the Tidal Unit, MSQ during June 1998. Pressure logger deployments, during the study, occurred during six sampling periods between July 2002 and November 2005. In most instances deployment was timed to coincide with spring tide cycles. Details of each deployment are shown in Table 1, including a brief description of the hydrologic setting, initial water depth at logger deployment and estimate of distance from nearest tidal source. In cases where there was permanent water forming a persistent basin, loggers were deployed on the substrate of the basin. Where the substrate was observed to be a more ephemeral type of basin, loggers were deployed in small pools to monitor changes in inundation in the pools. Where there was no evidence of a basin environment loggers were deployed exposed on the substrate surface.

\section{INSERT TABLE 1}

\subsection{Logger Data conversion to Water Depth}

The Greenspan loggers recorded raw pressure data converted to raw water depth. The raw depth data were corrected for ambient atmospheric pressure and initial deployment depth. The Ocean Sensor Systems wave gauges recorded raw data as pressure readings, which were initially converted to raw water depth values prior to correcting for ambient air pressure and initial depth conditions. Ambient air pressure data used for correcting raw water depth readings were provided by the Bureau of Meteorology at the Gold Coast Seaway Weather Station, located $10 \mathrm{~km}$ southeast of the study site. The method used for correcting these data is explained in detail in Knight et al. (2006).

\subsection{Data Analysis}

\subsubsection{Definitions}

Trigger height: As we were interested in tidal events that flood the mangroves we used the term 'trigger height' to describe the height of the lowest high tide that would start to flood an area of mangrove forest.

Percent exceedence: Percentage of high tides exceeding a given tide height. Percent exceedence was derived from high tide observations for the Gold Coast tidal station for the period January 1986 to December 2004.

Flooding tide cycle: a series of adjacent spring tides flooding into the mangrove forest system.

Flooding event: A series of flood tides exceeding a given trigger height were considered to be part of the one event only if 5 or fewer days separated any adjacent flooding tide at or above the trigger height. The number of flooding events was derived from the long-term observations data for the Gold Coast tidal station for the period January 1986 through to December 2004. The length of a flooding event was calculated as the number of days between the first trigger height tide and the last trigger height tide in a series of flood tides.

Unimpeded high tide: tide gauging locations where the full tidal expression occurred (i.e., where water depth was greater than the tidal range).

Range of tides used in the study: the high tide height range used was based on field observations where a lower value of $1.3 \mathrm{~m}$ was selected because it was lower than the lowest tide height that flooded the system 
(trigger height), higher than the mean high water neaps (MHWN $1.15 \mathrm{~m}$ ) and higher than the highest neap tide observed during the study, thereby minimising the potential of confounding caused by these lesser tides.

Analysing the Standard Port High Tide Dynamics

The Gold Coast tidal station semidiurnal tidal plane data were used as a basis for establishing relationships between tides at the Gold Coast standard port and tides in the study site - Coombabah Lake. The tidal plane was defined according to definitions published in Anon. (2005). Long-term high tide observation data were used to derive relationships between three tide height dynamics: number of tides above trigger height, the percent exceedence of high tides above trigger height and the number of high tide events.

\subsubsection{Predicting number and percent exceedence of high tides above trigger heights}

Trigger heights for tides were established by comparing water depths with published local tidal observations for the Gold Coast tidal station. Long-term high tide observation data between $1.3 \mathrm{~m}$ and $2 \mathrm{~m}$ (in $5 \mathrm{~cm}$ increments) were used to model the number and percent of high tides exceeding a range of tide height increments. These data were plotted and polynomial functions were fitted $\left(2^{\text {nd }}\right.$ order polynomial). The polynomials were used to estimate the number and percent of high tides exceeding the trigger heights observed in the study.

\subsubsection{Predicting number of discrete flooding events}

The long-term high tide observation database was used to estimate the number of discrete tidal flooding events, separated by more than 5 days of lower than trigger height tides, as in Equation 1.

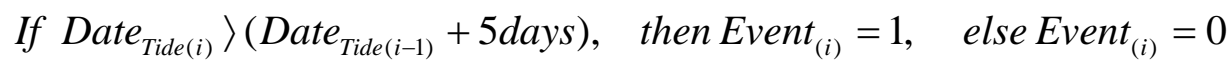

Where:

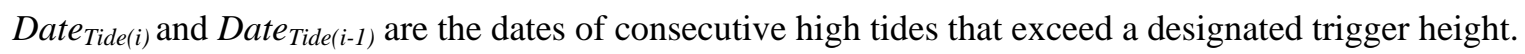

Event is a Boolean flag indicating high tides that are preceded by more than 5 days of lower than trigger height high tides.

The number of tidal flooding events for high tides between $1.3 \mathrm{~m}$ and $2 \mathrm{~m}$ (in $50 \mathrm{~mm}$ increments) was obtained by summing across the event record for each height interval. These data were plotted and a polynomial function ( $3^{\text {rd }}$ order polynomial) was fitted to the data from which numbers of flooding events for trigger heights observed during the study were estimated. 
Unimpeded tidal observations (observations from gauges located where full tidal expression occurred) from three spring tide surveys (June 1998 - site 19, September 2002 - site 6 and November 2005 - site 18) were used to identify high tide time lag and amplitude attenuation relationships between Coombabah Lake and the Standard Port (the Gold Coast tidal station).

To estimate the time lag between Coombabah Lake and the Standard Port, times of high tides (at a resolution of 10 minutes) from three unimpeded tide surveys, located at sites 6, 18 and 19, were compared with corresponding high tides from the Gold Coast tidal station. A Gold coast high tide minimum of $1.3 \mathrm{~m}$ relative to Lowest Astronomical Tide datum (LAT) was used as a cut-off for inclusion in the temporal analysis because this was considered low enough to include all flooding into the mangroves and minimised the possibility of confounding caused by differences in tide-time relationships at other tide stages (such as during neap tides) and for the reasons mentioned in section 2.4.1. above.

To estimate high tide amplitude attenuation at Coombabah Lake compared with the Standard Port, high tide heights for the three full amplitude Coombabah Lake surveys, located at sites 6, 18 and 19, were plotted against corresponding high tide observations for the Gold Coast tidal station. A linear function was fitted to each of the three datasets from which an average of the slope (1st derivative) was used an estimate of the attenuation in tide height amplitude at Coombabah Lake.

\subsubsection{Coombabah Lake Lake-edge Tidal Observations}

In order to identify differences in tidal pattern across the different mangrove forest sections at Coombabah Lake, hydroperiod data was compiled from individual tidal traces. For each pressure logger deployment, water heights before, during and after tidal flooding were identified from the tidal trace, as shown conceptually in Fig. 3. The conceptual model has two components: the hydro-structure (left) illustrates the type of relationship between water heights and hydroperiod data; and the tidal trace (right) illustrates two types of tidal flooding into basin forests contrasting impeded and unimpeded flooding. In the hydro-structure model horizontal lines are positioned to represent relative water height relationships in the vertical direction and temporal relationships are represented by position and length in the horizontal direction. Thus, for example, the minimum recorded water height (MRH) was always lower than or equal to the minimum water height prior to the first flooding tide (HPFT) and so the position of the HPFT line is temporally overlapping the MRH line and sloping upwards from the MRH line. In all recorded tide traces the MRH occurred prior to the first flooding tide thus its position at the left of both conceptual models in Fig. 3. In the tidal trace model the impeded trace shows the consequence of relatively poor connectivity to the tide source due to very dense pneumatophores (vertical aerating roots of Avicennia marina; see Table 2) in the impeded basin form. Also, there is a cumulative increase in water height with subsequent flooding tides (from first flooding tide (FFT) through to last flooding tide (LFT) to the top of the pneumatophores, above which, relatively unimpeded drainage occurs. In the case of the basin with unimpeded drainage (Fig. 3) connectivity to the tidal source is 
more efficient, however, there is still an increase in the base level water height due to tidal flooding but this is not cumulative over successive tides.

\section{INSERT FIG 3}

\section{Results}

\subsection{Forest types based on field observations}

The mangrove forest type surrounding each logger site plus a brief description of substrate form is recorded in Table 1 as part of the initial site condition description. All basin logger deployment sites were located between 100 and 550m, whereas all fringing / riverine logger site were between 30 and $40 \mathrm{~m}$ from the lake edge (Table 1).

Of the six mangrove forest forms described by Lugo and Snedaker (1974) only the basin hammock and dwarf forest forms were not identified within the Coombabah Lake wetlands. The approximate locations of the different forest forms identified in the study are shown in Fig. 2. The various basin areas shown in Fig. 2 are indicative only, as there was usually a transition from one type to another. A description of each forest form follows.

Overwash forests were found on two small islands located within the lake just north of site 18 (Fig. 2). The Overwash forest is relatively young with early photos (ca 1950s) showing the islands to be the same shape but almost entirely un-vegetated. Mangroves on these islands are now approaching $6 \mathrm{~m}$ in height are very densely spaced and are dominated by Avicennia marina.

Fringing forests were found extending from the lake edge around sites 15 and 17 and in a thin strip around much of the lake except in the northwest arm (Fig. 2). In many instances a low berm was found a few metres landward, however at sites 15 and 17 no berm was present. The fringing forest is dominated by Avicennia marina with rare instances of other mangrove species.

Riverine forests were found in the northwest arm of the lake (including around sites 2 and 8 ) where historic aerial photo evidence shows a creek line entering the lake at the northern end of the arm. The mangroves around site 2 and on the upstream banks of the lake (south of sites 15 and 16, Fig. 2) as the lake narrows into Coombabah Creek were much taller (up to $20 \mathrm{~m}$ ) with a mix of mangrove species as listed in section 2.1 above. The extent of riverine mangroves is shown in Fig. 2. It was generally found that the riverine forest was a relatively narrow strip of about $50 \mathrm{~m}$ associated with a berm.

Basin forests were identified in most areas on the landward side of fringing and riverine mangroves (such as around sites $1,10,11,12,13,14$ and 16) and usually there was an obvious berm between the edge forest and the beginning of the basin forest. Three sub-types of basin forest were identified using differences in water depth and substrate composition as described in Table 2. All areas of basin forests were found to be monocultures of Avicennia marina. 
1. Deep basin with relatively deep standing water greater than 0.3 to $0.5 \mathrm{~m}$ deep, has a substrate composed of water or dense pneumatophores, where the pneumatophores form a dense surface approximately $0.1 \mathrm{~m}$ above the average water level.

2. Medium depth basin with standing water up to greater than 0.15 to $0.3 \mathrm{~m}$ depth with a substrate composed of either water or pneumatophores with some exposed mud during non-flood conditions.

3. Shallow basin form was identified as standing water from 0.05 to $0.15 \mathrm{~m}$ deep, and substrate structure composed mainly of water and exposed mud during non-flood conditions, with a relatively low density of pneumatophores.

The berm associated with the shallow basin form was much less pronounced than for the two deeper basin forms. The central mangrove forest ranged between a deep basin in the northern part around site 9 and became progressively shallower to the south eventually ending as a relatively wide strip of fringing forest around site 17 (Fig.2). This transition corresponded to a decrease in berm significance where adjacent to site 9 the berm was $0.5 \mathrm{~m}$ higher than the adjacent basin levels, whereas near site 17 there was no berm evident.

\section{INSERT TABLE 2}

\subsection{Standard Port Description}

Details of the semidiurnal tidal plane for the Gold Coast tidal station are shown in Table 3. All high tides flooding the mangroves occurred on tides above mean high water springs (1.41 m MHWS) at the Gold Coast tidal station.

\section{INSERT TABLE 3}

The annual frequency of high tide heights recorded at the Gold Coast tidal station for the period 1986 through to 2004 are shown in Fig. 4. The annual frequencies range between 301 per year $(n=5730$, range 189 - 394, se 0.77 ) for tides $1.3 \mathrm{~m}$ and greater to 3.2 per year $(n=61$, range 1 - 14, SE 0.46) for tides $1.9 \mathrm{~m}$ and greater. Of the 61 tides equal to or greater than $1.9 \mathrm{~m}, 29$ occurred in a three-year period from 1999 (5, 14 and 10 tides per year respectively).

\section{INSERT FIG 4}

High tide percent exceedence data for Gold Coast tidal station high tides for the period January 1986 through to December 2004 are plotted in Fig. 5. A $2^{\text {nd }}$ order polynomial has been fitted to the data. Using the equation shown on Fig. 5, an estimated 31\% of high tides exceed the MHWS height of $1.41 \mathrm{~m}$ and only $0.45 \%$ of high tides exceed the highest astronomical tide (HAT) height of $1.89 \mathrm{~m}$. Given the semidiurnal 
nature of tides in southeast Queensland the number of tides around $1.30 \mathrm{~m}$ includes a number of lower high water tides each day as well as the higher high water tides.

\section{INSERT FIG 5}

The number of flooding events based on the long-term Gold Coast tidal station observation data set has been plotted on Fig. 6. A $3^{\text {rd }}$ order polynomial has been fitted to the data on Fig. 6 for tide heights between 1.3 and $1.9 \mathrm{~m}$. By solving the first derivative of the equation in Fig. 6, an estimate of the peak number of flooding events of 18.5 occurring at a tide height of $1.473 \mathrm{~m}$ was calculated. This compares well with a peak of 19.2 events occurring at a tide height of $1.5 \mathrm{~m}$ when derived from the long-term Gold Coast high tide observation data set.

\section{INSERT FIG 6}

\subsection{Coombabah Lake Unimpeded Tidal Observations}

An average time lag of 3 hours (standard error (SE) 4.1 minutes) was observed between high tides at the Gold Coast tidal station and high tides in Coombabah Lake using the average tide trace lags from Sites 6, 18 and 19 (Fig. 7). As would be expected the lag for site 6 (2hrs 35min, SE 8.1 minutes) located slightly downstream was less than the average lag. The lag for site 19 was slightly longer (3hours 10 minutes, SE 3.1 minutes) than the average, being located near the upstream extent of the lake.

The average attenuation of high tides in Coombabah Lake at $0.82\left(\mathrm{R}^{2}>0.9\right)$ is the average of the slopes of the three linear equations shown on Fig. 7. This compares well with the MSQ published attenuation of 0.84 for Saltwater Creek - Coomera river confluence, some $2 \mathrm{~km}$ downstream. The slope was used to estimate attenuation in preference to absolute differences because of the difficulty of accurately calibrating recorded heights to the Australian Height Datum (AHD).

\section{INSERT FIG 7}

\subsection{Coombabah Lake Lake-Edge Tidal Observations}

Tidal traces for selected sites have been plotted in Fig. 8 and corresponding features as depicted in the conceptual model (Fig. 3) have been presented in Table 4. In addition, corresponding data for tidal parameters related to the local standard port (Gold Coast tidal station) were also collated into Table 4 . The range of Gold Coast tide heights for which tidal flooding into mangrove areas occurred was found to be large, with considerable differences between mangrove forest types. At the highest tide extreme, the deep basin mangroves around sites 1 and 10 did not flood until exposed to a high tide of $1.856 \mathrm{~m}$ (see lowest flooding 
tide height for site 1D, Table 4). This compared with the fringing forest around site 17 that was flooded by a much lesser Gold Coast high tide of $1.5 \mathrm{~m}$. The relative frequency of such tides is indicated by the percent exceedence data (Table 4 ) where only $0.85 \%$ of tides exceeded the tide height required to flood the deep basin mangroves around site $1 \mathrm{D}$ and site 10 compared with $21.1 \%$ of tides expected to flood the fringing mangroves around site 17. In a number of instances (sites $1 \mathrm{~A}, 1 \mathrm{~B}, 3,4,5$ and 16) the trigger height at which tidal flooding occurs was not reached.

\section{INSERT TABLE 4}

\section{INSERT FIG 8}

Of the four groups of tide traces shown in Fig. 8 (labelled A-D), the fourth (D) from site 17 (located about $30 \mathrm{~m}$ from the lake edge, Table 1), showing a trace of tidal flooding into the fringing forest mangroves, best matches a typical unimpeded flood tide situation. Once at the trigger height flooding proceeds into the mangroves and then drains with the receding tide at a similar rate. There is little impediment to drainage, no residual backwater, with only a small time lag (30 min) between the tidal peak in the lake and in the fringing mangroves (Table 4). Whereas, flooding into the deep basin forest mangroves (Fig. 8A) (around sites 1D and 10 located 550 and $440 \mathrm{~m}$ respectively from the nearest lake edge, Table 1) comprised a relatively small rise in water height of $0.08 \mathrm{~m}$ across the two flooding tides with considerable time lags until peak flooding of 3 to 3.5 hours behind the peak in the lake. The rates of water level rise into the deep basin $(0.4$ and $0.3 \mathrm{~mm} / \mathrm{min}$ for sites $1 \mathrm{D}$ and 10 respectively, Table 4) are considerably less than rates into all other sites (Table 4). Also, in this deep basin area the tide traces (Fig. 8A) show almost no drop in water level (drainage) between successive flood tides suggesting no direct and/or unimpeded connection with the lake exists. The very high density of pneumatophore roots $\left(1365 \mathrm{~m}^{2}\right.$, Table 2$)$ forming a mat like surface about $0.1 \mathrm{~m}$ above the average water height is the likely reason for the relative isolation of the deep basin forest form.

The other two groups of tide traces shown (Fig. 8B and 8C) exhibit features of both the deep basin form and the fringing form. In these cases, after initial flooding, there is a net increase in basin water level some of which remains after the final flooding tide has receded. Also, the medium depth and shallow basin traces (sites 11 - 12, and 13 - 14, respectively) exhibit varying degrees of drainage between successive flood tides as shown by the longer curved form of the receding trace compared with the traces of the flooding phases. The time taken for tidal floodwater to drain varied considerably. Some sites (sites 8, 15 and 17, Table 4) receded to a relatively stable level in a few hours, whereas others (sites 11, 12, 13 and 14) took up to 15 hours to drain. In extreme cases (such as sites 1D, 7 and 10) the floodwater receded so slowly that water levels had not stabilised before the next flooding occurred.

A summary of the hydrologic characteristics of each of the mangrove forest is presented in Table 5. Gold Coast tidal station high tide trigger heights were identified for forest form and used to estimate typical 
flooding scenarios. In some instances two scenarios were identified for adjacent sections of forest. For example, comparing results for the contiguous section of mangroves associated with sites 9 and 17 shows that one functions as a basin system (site 9) with a trigger height of 1.753m and a flood duration of 5-6 hours (Table 4), while the other site (17) functions as a fringing system with a trigger height of $1.5 \mathrm{~m}$ and a flood duration as low as 1 hour (Table 4).

Table 5 compares the expected number of flood events per year (calculated from the equation in Fig. 6) with the number of flood events occurring per year derived from the Gold Coast long-term record of high tide data. This comparison is presented to give an indication of the reliability of estimates derived using the model with those from the long-term record.

The results indicated two main points: first, that the mangrove system at the study site is not always flushed by tides and second, that very distinct hydroperiod characteristics have been observed and that these relate to tidal height, substrate form and distance from the lake edge tide source.

\section{INSERT TABLE 5}

\section{Discussion}

A common assumption about mangrove forests is that they are regularly flushed by the tide. This is clearly a limited representation, as a wide range tidal flooding patterns and forest forms have interested mangrove researchers for some time. In the current study tidal flooding into the Coombabah Lake mangroves did not commence until the tide height reached higher than mean high water spring tide height (MHWS) $(>1.41 \mathrm{~m}$, Table 3) at the standard port. Using the gap in tide height between highest non flooding tide and lowest flooding tide, or trigger height (Table 5), gave an estimate of the tidal flooding characteristics of each of the forest types and basin sub types (Table 5). We discussed earlier (in Sect 1.) that mangrove inundation can be articulated in a number of ways. Watson (1928) described inundation in classes based on tide height and De Haan (1931) in terms of frequency of flooding, in order to understand the nature of tidal dynamics in mangroves. Chapman (1944) identified mangrove species against frequency of tidal flooding which was subsequently expanded to vegetation distribution (as belts or zones) mapped against tidal pattern (e.g. Macnae, 1966 and Chapman, 1976). Using these approaches did not prove particularly useful for describing the patterns of tidal flooding found at the Coombabah Lake study site. This was because only a relatively small range of tidal flooding classes were observed at the Coombabah Lake study site. For example when compared with Watson's (1928) schema we found only classes 4 and 5 (out of 5 classes), for De Haan's (1931) schema we found classes A3 and A4, and using Chapman's (1944) approach we found only the last two frequency groupings (250 and fewer submersions per year). All these classes correspond to tides higher than mean high water neap tides (MHWN, $>1.15 \mathrm{~m}$, Table 3) at the nearest standard port. One reason for the relatively low range of tidal flooding is the topographic form of Coombabah Lake within the broader landscape. Coombabah Lake is a depression in the coastal plain of Moreton Bay in southeast Queensland and is located approximately $18 \mathrm{~km}$ (see Fig. 7) from the nearest tidal source via tidal creeks and Moreton Bay. 
The local topography is relatively flat and much of the mangrove forested areas around the lake have the form of back basins separated from the lake by low berm formations.

With respect to mangrove species zonation, a monospecific forest of the grey mangrove (Avicennia marina var. australasica (Walp.)) was identified across the study site except for small areas of mixed species forest fringing some sections of the lake. The species distribution mix at Coombabah Lake does not lend itself to the species zonation approach as a means of understanding the hydrodynamics of the study area. This is because the typical zonation approach links the pattern of tidal flooding (from frequent to infrequent flooding) to a transition of mangrove species through to saltmarsh and then salt flat as one proceeds up the topographic profile. Where as, in the present study there is a transition from fringing mangroves to shallow basin through to a relatively deep basin corresponding with declining frequency of tidal flooding.

Considerable support for the ecosystem approach of Lugo and Snedaker (1974) was found, as described in section 3.1, where four of their six forest forms were identified in the present study. Given the relatively flat topography and monospecific vegetation cover, adopting an ecosystem approach (such as Lugo and Snedaker) using mangrove formation and physiognomy, proved a useful way of describing the patterns of tidal inundation observed in the tide data. In assessing the range of substrate composition and standing water depth in the basin forests surrounding Coombabah Lake, three sub-types of basin not previously reported were identified. The basin sub-types were found to exhibit distinct tidal flooding patterns in terms of frequency of tidal flooding, ranging from 81 high tides per year to fewer than 3 high tides per year (Table 5) that correspond to a range of tide heights at which flooding into the mangroves commences (Table 5).

Other studies that have reported time lag evidence that dense pneumatophores may impede water movement (such as Mazda et al., 2005; Darboux et al., 2002; Mazda et al., 1997; Wolanski, 1992; Furukawa and Wolanski, 1996) have linked water flow variation to mangrove forest basin form. In this study increasing forest structural development (increasing tree density, tree height and DBH, Table 2) corresponds with an increase in the density of pneumatophores and the proportion of substrate comprised of pneumatophores (Table 2). The average pneumatophore density (1365 $\mathrm{m}^{-2}$, Table 2) in the deep basin area formed island like structures comprised almost entirely of pneumatophores around individual mangrove trees, often forming aggregations of contiguous pneumatophore substrate many hectares in area, with occasional open water areas interspersed. With an estimated height above the average basin water depth of around $10 \mathrm{~cm}$, dense pneumatophore areas appeared to provide considerable dampening of tidal flooding as depicted in the case of the basin with impeded drainage in the conceptual model shown in Fig. 3B. The tidal traces shown in Fig. 8A exhibited a pattern of tidal flooding where a significant backwater (or accumulation of water between tides) occurred with subsequent flooding tides. This pattern of tidal flooding in the deep basin was structurally different from that of the medium and shallow basin forms because there was no notable backwater accumulation with subsequent flooding tides (comparing Fig. 8A with Fig. 8B\&C) in these cases. The patterns of tidal flooding as shown by the tidal traces in Fig. 8 reflect a pattern in mangrove substrate development from an open relatively unimpeded case of the shallow basin (Fig. 8C) to one of increasing closure and loss of connection as the forest matures (Fig. 8B to Fig. 8A). 
Ongoing research (by Knight, Dale and others) suggests that the three basin classes described in this research (shallow, medium and deep basins) result from mangrove forest development over the past 60 or so years, where the deep basin areas were the first to establish as mangroves (based on unpublished interpretation of 1944 aerial photos) and now exhibit the most advanced tree and substrate development. The shallow basin areas represent much more recent expansion of mangroves at the landward edge of the lake system. This also corresponds to a trajectory of increasing water depth over the same period. The area currently identified as deep basin forest (Fig. 2) appeared in 1944 as saltmarsh and salt flat with no standing water. This area now has $\sim 50 \mathrm{~cm}$ of standing water. Similar patterns of water depth change have been observed for the other basin types in the study area. Reasons for the increasing water depth in the lake edge mangroves over time are also the subject of on going research (by Knight, Dale, Lemckert, Broadbent and others) with analysis of tidal observation data from the 1960's and analysis of soil cores take from the site.

There are limitations to the research. One is on the use of trigger height as we define it, as tidal conditions between the Gold Coast tidal station and Coombabah Lake can vary considerably because of extremes in local conditions such as high winds and heavy rainfall. The latter was considered important by Perdomo et al. (1998) and rainfall can be the driver of water level change especially during intense local storms where local runoff causes local flooding as water flows from higher areas towards the lake and creek system (Knight, unpublished data) contrasting with tidal flooding which is the reverse. Trigger heights should be used only as indicators of potential flooding, with some variability inherent in the estimates.

The wider scientific and management community potentially benefits from this research because it has contributed to the identification of the complex relationships between mangrove micro-topography and tidal influences. The research has identified three discrete types of mangrove basins related to tidal flooding, in what has tended to be seen as an homogeneous mangrove forest.

\section{Acknowledgements}

We thank the reviewers for their helpful and thoughtful comments and suggestions. We thank Assoc Prof Stuart Phinn, Nicole Shepherd and Dr Samuel Marx (University of Queensland) for reviewing the paper. We thank the Cooperative Research Centre for Coastal Zone and Estuary Management, University of Queensland (School of Geography, Planning and Architecture) and Griffith University, (Griffith School of Environment, Nathan) for funding and in kind support for this project. We thank the following who helped with practical work: at various times Samuel Marx, Brendan Nerdal and Nicholas Webb, Nick Cartwright. We thank the Gold Coast City Council and Howard Taylor for enabling access to the study site. The Bureau of Meteorology (Queensland) provided air pressure data for the Gold Coast Seaway weather station. Finally, we thank the Tidal Unit at Maritime Safety Queensland for tidal observations data provided for this research.

\section{References}

Anon., 2005. The Official Tide Tables and Boating Safety Guide 2005. Maritime Safety Queensland, Brisbane, Australia. 
Chapman, V.J., 1944. 1939 Cambridge University Expedition to Jamaica. Journal of the Linnean Society Botany (London) 52, 407-533.

Chapman, V.J., 1976. Mangrove Vegetation. J. Cramer, Vaduz, 425pp.

Cohen, M.C.L., Lara, R.J., Szlafsztein, C., Dittmar, T., 2004. Mangrove inundation and nutrient dynamics from a GIS perspective. Wetlands Ecology and Management 12(2), 81-86.

Darboux, F., Davy, Gascuel-Odoux, C., Huang, C., 2002. Evolution of soil surface roughness and flowpath connectivity in overland flow experiments. Catena 46(2-3), 125-139.

De Haan, J.H., 1931. Het een en ander over de Tijlatjapsche vloedbosschen. Tectona 24, 39-75.

Dowling, R.M., Stephens, K.M., 2001. Coastal Wetlands of Southeast Queensland: Mapping and Survey. Qld Herbarium. 1, 222.

Furukawa, K., Wolanski, E., 1996. Sedimentation in mangrove forests. Mangroves and Salt Marshes 1, 3-10.

Furukawa, K., Wolanski, E., Mueller, H., 1997. Currents and sediment transport in mangrove forests. Estuarine, Coastal and Shelf Science 44, 301-310.

Lara, R.J., Cohen, M.C.L., 2006. Sediment porewater salinity, inundation frequency and mangrove vegetation height in Bragança, North Brazil: an ecohydrology-based empirical model. Wetlands Ecology and Management 14, 349-358.

Knight, J.M., Dale, P.E.R., Dunn, R.J.K., Lemckert, C.J., 2006. Patterns of tidal flushing at the mangrove fringe of the lake. In: Lee, S.Y., Connolly, R.M., Dale, P.E.R., Dunn, R.J.K., Knight, J.M., Lemckert, C.J., McKinnon, S., Powell, B., Teasdale, P.R., Welsh, D.T., Young, R., The impact of urbanisation on coastal wetlands: a case study of Coombabah Lake, southeast Queensland. Cooperative Research Centre for Coastal Zone, Estuary and Waterway Management, Indooroopilly, Australia, Technical Report 54, 129155. Available online, http://www.coastal.crc.org.au/pdf/TechnicalReports/54-coombabah.pdf (accessed 12 July 2007).

Lugo, A.E., Snedaker, S.C., 1974. The Ecology of Mangroves. Annual Review of Ecology and Systematics 5, 39-64.

Macnae, W., 1966. Mangroves in Eastern and Southern Australia. Australian Journal of Ecology 14, 67104.

Mazda, Y., Kanazawa, N., Wolanski, E., 1995. Tidal asymmetry in mangrove creeks. Hydrobiologia 295, 51-58.

Mazda, Y., Kobashi, D., Okada, S., 2005. Tidal-Scale Hydrodynamics within Mangrove Swamps. Wetlands Ecology and Management 13(6), 647-655. 
Mazda, Y., Wolanski, E., King, B., Sase, A., Ohtsuka, O., Magi, M., 1997. Drag force due to vegetation in mangrove swamps. Mangroves and Salt Marshes 1, 193-199.

Perdomo, L., Ensminger, I., Espinosa, L.f., Elster, C., Wallner-kersanach, M. and Schnetter, M.-L., 1998. The Mangrove Ecosystem of the Cienaga Grande de Santa Marta (Colombia): Observations on Regeneration and Trace Metals in Sediment. Marine Pollution Bulletin 37(8-12), 393-403.

Varnell, L.M., Evans, D.A., Havens, K.J., 2003. A geomorphological model of intertidal cove marshes with application to wetlands management. Ecological Engineering 19(5), 339-347.

Watson, J.G., 1928. Mangrove Forests of the Malay Peninsula. Malasian Forest Records 6, 1-275.

Wolanski, E., 1992. Hydrodynamics of mangrove swamps and their coastal waters. Hydrobiologia 247, 141-161.

Wolanski, E., Jones, M., Bunt, J.S., 1980. Hydrodynamics of a tidal creek-mangrove swamp system. Australian Journal of Marine and Freshwater Research 31, 431-450. 